\title{
When small RNAs become smaller: emerging functions of snoRNAs and their derivatives
}

\author{
Anna M. Mleczko and Kamilla Bąkowska-Żywicka \\ Institute of Bioorganic Chemistry Polish Academy of Sciences, Poznań, Poland
}

\begin{abstract}
Small nucleolar RNAs (snoRNAs) are molecules located in the cell nucleolus and in Cajal bodies. Many scientific reports show that snoRNAs are not only responsible for modifications of other RNAs but also fulfill multiple other functions such as metabolic stress regulation or modulation of alternative splicing. Full-length snoRNAs as well as small RNAs derived from snoRNAs have been implied in human diseases such as cancer or Prader-Willi Syndrome. In this review we describe emerging, noncanonical roles of snoRNAs and their derivatives with the emphasis on their role in human diseases.
\end{abstract}

Key words: small RNAs, snoRNAs, sdRNAs, microRNAs, regulatory RNAs

Received: 30 May, 2016; revised: 28 July, 2016; accepted: 08 August, 2016; available on-line: 26 October, 2016

\section{INTRODUCTION}

Small nucleolar RNAs (snoRNAs) are one of the most ancient and evolutionarily conserved non-protein coding RNAs. They have been identified in Eukaryotes, Archaea and one in the Epstein-Barr virus (Hutzinger et al., 2009). There are two classes of snoRNAs (C/D and $\mathrm{H} / \mathrm{ACA}$ box) that function as ribonucleoprotein (RNP) complexes to guide enzymatic modifications of other RNAs, mainly ribosomal RNAs (rRNAs). Posttranscriptional rRNA modifications are common for all domains of life; there are three basic types: base methylation, ribose methylation and pseudouridylation.

C/D box snoRNAs take their name from the conserved sequence elements that they contain, known as C/C' (RUGAUGA, R=purine) and D/D' (CUGA) boxes, located near the 5' and $3^{\prime}$ ends of the snoRNA, respectively. C/D box snoRNAs form a ribonucleoprotein complex with 2'-O-methyltransferase fibrillarin and such snoRNP complex methylates the target RNAs. A conserved region of 10-21 nucleotides (nt) upstream of the $\mathrm{D}$ and/or D' box is complementary to the methylation site of the target RNA and enables the snoRNA to form an RNA duplex with the RNA. H/ACA box snoRNAs in turn form complexes with the pseudouridine synthase dyskerin and perform pseudouridylation. Small nucleolar RNAs from this class are built by two stems that form a pseudouridinilation pocket and two single stranded regions that enclose the $\mathrm{H}$ (ANANNA) and ACA elements.

Many studies have investigated snoRNA-guided modifications. As a result, some features characterizing the functional snoRNA-target site interactions have been inferred and are used in the computational prediction of snoRNA targets (e.g. sequence complementarity be- tween putative target RNAs and the antisense elements or the recognition loops within the snoRNA) as well as biochemical identifications of snoRNA targets (e.g. based on CLASH: crosslinking, ligation, and sequencing of hybrids). However, there are numerous snoRNAs for which no target RNAs have been identified so far. They are called "orphan snoRNAs". In multiple cases, orphan snoRNAs possess the guide sequences, however, they are not complementary to other canonical RNAs targeted by snoRNAs.

Small nucleolar RNAs were initially discovered in the nucleolus and were thought to exclusively target ribosomal RNAs inside this subnuclear compartment. However, years of research on the snoRNA biology have revealed a tremendous number of unexpected discoveries that shed a new light on their functions in processes different than modifications of other RNAs. Small nucleolar RNAs may take part in the regulation of metabolic stress responses, development of some diseases or disorders, like cancer or the Prader-Willi syndrome. Moreover, there is a growing number of evidence that mature snoRNAs undergo further processing into stable shorter fragments, known as snoRNA-derived RNAs (sdRNAs) (Falaleeva \& Stamm, 2013; Li et al., 2012). Such fragments are present in many organisms, including mammals (Bortolin-Cavaille \& Cavaille, 2012; Kishore et al., 2010; Ender et al., 2008; Bai et al., 2014; Brameier et al., 2011; Burroughs et al., 2011), a primitive protozoan Giardia lamblia (Saraiya \& Wang, 2008), budding yeast Saccharomyces cerevisiae (Żywicki et al., 2012; Walkowiak et al., 2016) and the Epstein-Barr virus (Hutzinger et al., 2009). Interestingly, these fragments associate with proteins different than the full-length snoRNAs do, and therefore possibly fulfill distinct cellular functions. Moreover, such snoRNA cleavage in yeast cells is most prominent under non-optimal growth conditions, which include UV irradiation, anaerobic growth, growth in a high or low $\mathrm{pH}$

e-mail: bakowska@ibch.poznan.pl

Abbreviations: 5-HT2CR, 5-hydroxytryptamine receptor 2; Ago, Argonaute protein; CRHR1, corticotropin-releasing hormone receptor 1; EBV, Epstein-Barr virus; DPM2, dolichol phosphate-mannose biosynthesis regulatory protein; HEK293, human embryonic kidney 293 cells; hnRNP, heterogeneous nuclear ribonucleoprotein; HNSCC, head and neck squamous cell carcinomas; MAPK/ERK, mitogen-activated protein kinases; originally called ERK, extracellular signal-regulated kinases; miRNA, microRNA; mRNA, messenger RNA; ncRNA, non-protein coding RNA; NGS, next generation sequencing, NSCLC, non-small-cell lung carcinoma; PBRM1, protein polybromo-1; PCR, polymerase chain reaction; PWS, Prader-Willi syndrome; qRT-PCR, quantitative real-time reverse transcriptase PCR; RALGPS1, Ral GEF with $\mathrm{PH}$ domain and $\mathrm{SH} 3$ binding motif 1 protein; RNP, ribonucleoprotein complex; rRNA, ribosomal RNA; sdRNA, small RNA derived from snoRNA; SL-RT-PCR, stem-loop reverse transcription combined with polymerase chain reaction; snoRNA, small nucleolar RNA; TAF1, transcription initiation factor TFIID subunit 1 ; TGF- $\beta$, transforming growth factor $\beta$ 
medium or growth in a medium with no amino acids or sugars (Żywicki et al., 2012; Tyczewska et al., 2016). Such response to changing environment may therefore indicate that snoRNA processing may play a crucial role in the stress-dependent metabolism regulation, similar as in case of tRNA processing (Mleczko et al., 2014). In this article, we highlight the current state of the art concerning non-canonical roles of snoRNAs and their derivatives, sdRNAs, with emphasis on their role in human disorders.

\section{PROCESSING OF SNORNAS TO sdRNAs - DISCOVERING NOVEL FUNCTIONS OF KNOWN RNAS}

In 2008, an unbiased sequencing study (aimed at capturing all potential human small RNAs in a range of $19-40 \mathrm{nt}$ ) led to the observation of specific processing and accumulation of small RNAs originating from well-characterized non-coding RNAs, including snoRNAs (Kawai et al., 2008). In the next year, by systematic analyses of deep-sequencing libraries from diverse eukaryotic organisms, Taft and coworkers (2009) revealed that small RNAs with evolutionarily conserved size and position, are derived from the vast majority of snoRNA loci in animals (human, mouse, chicken, fruit fly), thale cress and fission yeast. Later on, a comparison of human small RNA deep sequencing data sets revealed that box C/D sdRNA accumulation patterns are conserved across multiple cell types (Scott et al., 2012). Recently, in 2014, Laiho and coworkers performed deep sequencing of small RNomes in subcellular compartments of the HeLa cells (Bai et al., 2014). The nucleolar small RNAs were predominantly represented by 19-20 nt and $25 \mathrm{nt}$ reads and $93 \%$ of them were mapping to the box C/D snoRNAs. The most abundantly represented locus among the sdRNA reads in the nucleolar fraction was

Table 1. The list of discovered snoRNA-derived RNAs.

\begin{tabular}{|c|c|c|}
\hline Organism & Processed snoRNA & References \\
\hline Epstein-Barr virus & v-snoRNA1 & Hutzinger et al., 2009 \\
\hline Giardia lambia & GlsR17, GlsR2 & Saraiya \& Wang, 2008; Li et al., 2011 \\
\hline Saccharomyces cerevisiae & $\begin{array}{l}\text { snoRNA: } 78,77,128,51,76,17 a, 66,67,73,18,54,83,30 \\
8\end{array}$ & $\begin{array}{l}\text { Żywicki et al., } 2012 \\
\text { Walkowiak et al., } 2016\end{array}$ \\
\hline Mus musculus & MBII-52 & $\begin{array}{l}\text { Kishore et al., 2010; Bortolin-Cavaille \& } \\
\text { Cavaille, } 2012\end{array}$ \\
\hline Homo sapiens & $\begin{array}{l}\text { ACA45, ACA36B, ACA56, ACA3, ACA17, ACA50, ACA47, } \\
\text { ACA25, RNU44, SNORD48, SNORD21, SNORA48, } \\
\text { SNORA64,SNORA73, SNORA8, } \\
\text { SCARNA15, SCARNA15, snR39b, H/MBII-52, HBI-100, HBII- } \\
\text { 336, HBIl-429, HBII-142, U27, U83a, U74, U15a. U92, U3, } \\
\text { U78, U17a, U17b, sno-miRNA-28, hsa-miRNA-1291 }\end{array}$ & $\begin{array}{l}\text { Bortolin-Cavaille \& Cavaille, 2012; Kishore } \\
\text { et al., 2010; Ender et al., 2008; Bai et al., } \\
\text { 2014; Brameier et al., 2011; Burroughs et } \\
\text { al., 2011; Yu et al., 2015, Pan et al., } 2013\end{array}$ \\
\hline $\begin{array}{l}\text { Canis familiaris } \\
\text { Rattus norvegicus } \\
\text { Mus musculus } \\
\text { Canis familiaris }\end{array}$ & ACA45 & Ender et al., 2008 \\
\hline embryonic chicken cell line & GSE10686, GSM270187, GSM270188, GSM270189 & Taft et al., 2009 \\
\hline $\begin{array}{l}\text { mouse embryonic stem (ES) } \\
\text { cells }\end{array}$ & GSE12521, GSM314552, GSM314553, GSM314552 & Taft et al., 2009 \\
\hline Drosophila melanogaster & $\begin{array}{l}\text { GSE7448, GSM180328, GSM180329, GSM180330, } \\
\text { GSM180331, GSM180332, GSM180333, GSM180334, } \\
\text { GSM180335, GSM180336, GSM180337, GSE11086, } \\
\text { GSM280082, GSM280083, GSM280084 }\end{array}$ & Taft et al., 2009 \\
\hline Arabidopsis thaliana & $\begin{array}{l}\text { GSE12037, GSM304282, GSM304283, GSM304284, } \\
\text { GSM304285 }\end{array}$ & Taft et al., 2009 \\
\hline Schizosaccharomyces pombe & GSE12416, GSM311595, GSM311596 & Taft et al., 2009 \\
\hline
\end{tabular}
Few of the sdRNAs were detected in the cytoplasmic fraction, which could suggest their functional potential in processes different than those in which the mature precursors act (since full-length snoRNAs are localized and perform their function in the nucleolus). The list of discovered snoRNA-derived small RNAs is presented in Table 1.

Concerning the function of sdRNAs in the cells, the first and breakthrough functional study came from the Meister group. It demonstrated the miRNA-like activity of an sdRNA originating from ACA45 snoRNA (Ender et al., 2008). This particular sdRNA was identified in the Ago-associated RNA library. Importantly, the sequencing reads were found to be conserved in mammals, suggesting that they are, indeed, specific processing products. In terms of both, processing and function, ACA45 sdRNA was similar to miRNAs. Firstly, this sdRNA was produced in the HEK293 cells in a Dicer-dependent manner. Secondly, an endogenous target RNA has been identified (CDC2L6 - a component of the mediator complex) and experimentally confirmed. ACA45 sdRNA was able to inhibit the activity of a CDC2L6 target in a miRNA-like pattern. Notably, the same authors identified seven additional sdRNAs with miRNA-like processing features in the follow-up experiments. Parallel NGS studies of the small transcriptome in mice revealed the presence of snoRNA-originating miRNA-like molecules in embryonic stem cells and demonstrated that sdRNAs exhibit tissue specific expression (Babiarz et al., 2008; Babiarz et al., 2011).

At the same time, two functional snoRNA-originating miRNA-like RNAs were described in the protozoan Giardia lamblia, a unicellular parasite whose genome does not encode Drosha: miRNA2 (Saraiya \& Wang, 2008) and miRNA5 (Li et al., 2011). These miRNA-like sdRNAs associated with the Ago proteins and were pro-
SNORD44 (RNU44) - 71.4\% of all nucleolar sdRNAs.

源, , ( , U17a, U17b, sno-miRNA-28, hsa-miRNA-1291 
$\mathrm{ACA} 45$

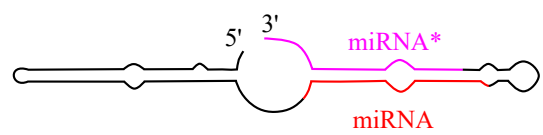

GlsR16

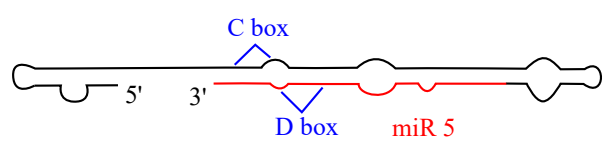

GlsR17

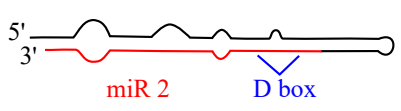

V-snoRNA1

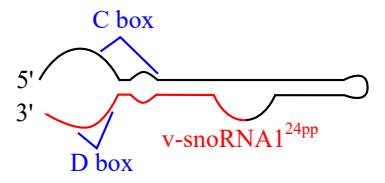

Figure 1. Examples of sdRNAs with microRNA functions.

Predicted secondary structures of the following snoRNAs are presented: human ACA45, G. lamblia GIsR17 and GIsR16, EBV v-snoRNA1. microRNA positions are marked in red. For $C / D$ box snoRNAs, $C$ boxes and $D$ boxes are marked in blue.

duced in a Dicer-dependent but Drosha-independent manner. 26-nucleotide long miRNA2 is a processing product of GlsR17 snoRNA and is localized in the cytoplasm. miRNA5 of the same length is derived from a C/D box snoRNA, GlsR2. In this case the authors also identified a putative miRNA target sites in the 3'-UTRs of mRNAs and verified the activity of miRNA2 in vivo. The expression of Renilla luciferase (RL) reporter mRNA containing six identical miRNA2 target sites in the 3'-UTR was reduced by $40 \%$ when co-transfected with miRNA2 (Saraiya \& Wang, 2008). Moreover, Li et al. took the same approach and discovered that the presence of endogenous miRNA5 in Giardia reduces the RL expression by $18 \%$, whereas the presence of additional synthetic miRNA5 further decreases the expression by a total of 39\% (Li et al., 2011). The same pathway was described one year later in cells infected with the Epstein-Bar virus (EBV). In this system, EBV expresses a miRNA-like precursor endogenously encoded by a viral v-snoRNA1 to suppress the viral DNA polymerase upon induction of the lytic cycle (Hutzinger et al., 2009). Numerous miRNAs-like molecules derived from C/D box snoRNAs which exhibit mRNA silencing features were additionally identified in human cell lines: HeLa, Jurkat ( $\mathrm{T}$ cells) and RPMI8866 (B cell) (Brameier et al., 2011). 11 RNAs derived from SNORD2 (snR39b), SNORD3@(U3), SNORD78 (U78), SNORD93 (HBII336), SNORD100 (HBII-429), SNORD66 (HBII-142), SNORD27 (U27), SNORD83a (U83a), SNORD74 (U74) and SNORD15a (U15a) were capable of translation regulation of reporter-gene mRNAs. Three other miRNAlike RNAs turn out to be cleaved from H/ACA box snoRNAs and they also regulated expression of the reporter gene. What is of special importance, the silencing activity differed among all investigated cell types. Representatives of the experimentally validated functional miRNA-like sdRNAs and their position within the secondary structures of snoRNA counterparts are presented in Fig. 1.

Recent research aiming at deep sequencing of small non coding RNAs from patients with prostate cancer and normal prostate at different disease stages, shed a new light on the importance of snoRNA fragments in cancer tissues (Martens-Uzunova et al., 2015). Surprisingly, it turned out that at least 78 of the detected sdRNAs, including SNORD44, SNORD78, SNORD74 and SNORD81, demonstrate a strong differential ex- pression in prostate cancer patients, which was even stronger than in the case of miRNAs. Most of sdRNAs originated from equivalent locations of their precursors and often one predominant sdRNA was observed per precursor snoRNA. High levels of SNORD78 in a patient who developed metastatic disease suggested that this sdRNA could be a novel prognostic biomarker for the prostate cancer patients with a high risk of developing metastasis. What is worth to mention, Martens-Uzunova and coworkers also discovered that the tRNA fragments could be present in high amounts in metastatic samples (Martens-Uzunova et al., 2012).

The p53 protein is an tumor suppressor gene and it plays a crucial role in the prevention of oncogenic transformation. In 2015, Nielsen and his group published novel and unobvious results demonstrating a role for p53 in repression of a family of polycistronic C/D box snoRNAs, of which at least one is processed into an operative miRNA-like RNA ( $\mathrm{Yu}$ et al., 2015). This snoRNA fragment represses TAF9B-mediated stabilization of p53 and promotes cell proliferation, which in turn leads to breast cancer.

Moreover, snoRNA-derived miRNAs can also modulate cellular drug disposition (Pan et al., 2013). The hsamiRNA-1291 is a small non-coding RNA derived from H/ACA SNORA34 which modulates cellular drug disposition and chemosensitivity through binding to the 3'UTR of $A B C C 1 \mathrm{mRNA}$ and negative regulation of its expression. $\mathrm{ABCC} 1$ is a membrane transporter that is expressed ubiquitously in human tissues and contributes to cellular disposition of numerous xenobiotics. Such regulation of ABCC1 expression is responsible for a significantly increased level of intracellular drug accumulation and chemosensitivity. Furthermore, it has been found that hsa-miRNA-1291 is significantly downregulated in human pancreatic ductal adenocarcinoma, when compared to normal pancreas. Better understanding of regulation of $\mathrm{ABC}$ transporters might therefore help to develop a rational drug therapy for cancer patients.

Interestingly, using an alternative computational approach for non-coding RNA detection based on the properties of promoter regions of well-characterized ncRNAs, in $2015 \mathrm{Qu}$ et al. were able to detect two dicistronic genes encoding precursors that are processed into mature snoRNA and miRNA molecules in Arabidopsis thaliana (Qu et al., 2015). Both, the snoRNAs and the miRNA transcribed from the two identified dicistronic snoRNA-miRNA775 and sno-miRNA779 genes have a common precursor and they use two distinct maturation pathways that preserve the integrity of both ncRNAs.

Although the components of the machinery necessary for miRNA action are conserved in diverse eukaryotic species, including budding yeast Saccharomyces castellii and Candida albicans, they have been lost in the budding yeast Saccharomyces cerevisiae (Houseley et al., 2008). However, the presence of snoRNA processing products was demonstrated by high throughput sequencing studies and further validated with small RNA detection techniques in $S$. cerevisiae. Although yeast sdRNAs were observed in very low abundance in small-RNA sequencing studies (Zywicki et al., 2012), they could be easily detected with 


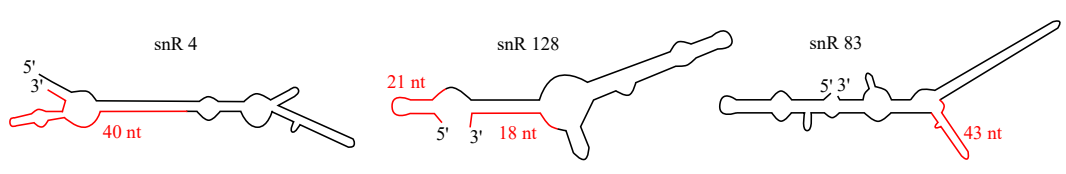

Figure 2. Atypical sdRNAs in Saccharomyces cerevisiae.

Predicted secondary structures of the following snoRNAs are presented: snR 4, snR 128 and SnR 83. sdRNA positions as well as their length are marked in red. Different types of sdRNA locations within the secondary structure of snoRNAs: 3'-part-derived, 5'-partderived or middle-part-derived.

stem-loop RT-PCR (SL-RT-PCR) method with as little as $50 \mathrm{ng}$ of low molecular weight RNA (Walkowiak et al., 2016). These results confirmed the presence of shortened version of both types of snoRNAs (C/D and $\mathrm{H} /$ ACA box) in baking yeast. The processing events were most prominent under non-optimal yeast growth conditions. What is interesting, yeast snoRNA fragments have different length than typical microRNA-like sdRNAs, ranging from $18 \mathrm{nt}$ to $43 \mathrm{nt}$ and the processing sites may be located within the 3' part of snoRNA, 5' part, both of them or snoRNA middle part (Fig. 2). What is of special importance, these sdRNAs have been co-purified with the yeast ribosomes (Zywicki et al., 2012). Therefore, the sdRNA/ribosome association might implicate a novel, yet undiscovered regulatory role of sdRNAs in ribosome biosynthesis and/or function in S. cerevisiae, independent from the microRNA-like pathway. Considering the fact that $30 \%$ of known genes involved in human diseases have yeast orthologs, and that the oxidative stress has been linked to diseases such as cancer, or to aging processes, sdRNA interactions with ribosomes in yeast might improve our understanding of defense mechanisms ranging from microorganisms to humans. Possible functions of snoRNA-derived fragments are summarized in Table 2.

\section{SnORNAs IN MALIGNANCY DEVELOPMENT}

Cancer is one of the major causes of human death, accounting for 8.2 million deaths in 2012 worldwide (World Health Organization statistics). It is therefore of crucial importance to identify and characterize the genetic alterations causing distinct types of cancer. One of the processes that could lead to the transformation of normal cells into the tumor cells are defects in ribosome maturation and function. Ribosomal RNA biogenesis is known to be more robust in cancer cells than in normal cells (Belin et al., 2009). Since snoRNAs are involved in the regulation of ribosomal RNA modification, it is therefore logical to suspect their possible roles in cancer development. It can be assumed that increase in the snoRNA levels is necessary for the acceleration of rRNA maturation, ribosome assembling and protein synthesis during tumorigenesis. Indeed, in 2002 Chang and coworkers showed for the first time that snoRNAs are involved in the development of cancer (Chang et al., 2002). They found that h5sn 2 snoRNA which belongs to $\mathrm{H} / \mathrm{ACA}$ box family was highly expressed in normal brain but its expression was reduced in meningioma, pointing that loss of snoRNA h5sn 2 is involved in brain tumorigenesis.

snoRNAs have been also found to be involved in development of the non-small-cell lung cancer (NSCLC), which is the leading cause of cancer deaths in the world (1.59 million deaths in 2012, according to the World Health Organization). Unfortunately, for most patients the available treatments are not sufficient, which clearly provides the reason for improving the NSCLC early detection. In 2010 Liao and coworkers presented the first study which globally analyzed the snoRNA expression patterns in human tumor tissues (Liao et al., 2010). Interestingly, the set of snoRNAs was overexpressed in the lung tumor tissue and compared with their normal counterparts. In this study, Liao and coworkers proposed a potential diagnostic test for NSCLC by measuring plasma snoRNA expressions by real-time quantitative reverse transcriptase PCR (qRT-PCR). Later on, the function of one of the overexpressed H/ACA box snoRNAs, SNORA42 (U42) was studied in greater detail (Mei et al., 2012). siRNA knockdown of SNORA42 resulted in a reduced cancer cell growth and compromised tumorigenicity in animal models by inducing p53-dependent apoptosis. On the contrary, overexpression of SNORA42 activated cancer cell growth. Moreover, the expression level of SNORA42 in lung tumor tissue specimen was found to be inversely correlated with the survival of NSCLC patients. In 2015, a significant upregulation of SNORD78 (U78) levels in NSCLC tissues was observed by Zheng and coworkers (2015). In this case, silencing of SNORD78 expression inhibited cell proliferation by inducing the phase G0/G1 arrest and cell apoptosis.

snoRNA expression profiling may be useful in the diagnosis of some subtypes of Peripheral T-cell lymphoma and the prognostication of cancer patients treated with chemotherapy. In 2012, it has been revealed that multiple snoRNAs are globally down-regulated in the T-cell lymphoma cells when compared with normal tissues; the same was also observed for miRNA (Valleron et al., 2012). Particularly interesting was the prognostic value of SNORD71 (HBII-239) snoRNA, which was significantly overexpressed in the case of angio-immunoblastic T-cell lymphoma and Peripheral T-cell lymphoma that were not otherwise specified. Such overexpression predicts a good prognosis for patients. What is also worth to mention, the SNORD71 fragment (which was called miRNA-768) is also overexpressed in tissues of patients with good prognosis and can be a powerful prognostic tool.

Another example of snoRNA downregulation in tumor cells comes from the research on hepatocellular carcinoma (Xu et al., 2014). Lowered expression of SNORD113-1 was correlated with cancer progression, cancer development and patient survival. Functional analyses revealed that overexpression of this snoRNA inhibited viability, tumorigenicity and cell growth of tumor cells, probably by the MAPK/ERK and TGF- $\beta$ pathway-dependent mechanisms. Hence, SNORD113-1 was proposed to be not only a potential diagnostic tool for hepatocellular cancer but also a potential therapeutic target.

One of the most common mutations causing many different types of human cancers, including breast and prostate cancer, is a deletion of chromosome 6 and its q14-q22 fragment (Dong, 2001). In 2008, Dong and his group revealed that SNORD50a (U50) gene can act as a 6q tumor suppressor (Dong et al., 2008). They have discovered that a 2-bp germline homozygous deletion of SNORD50a was associated with clinically significant prostate cancer. What is more, one year later the same group revealed that deletion of SNORD50a leads to de- 
Table 2. Examples of diverse snoRNA and sdRNA functions with emphasis on human diseases.

\begin{tabular}{|c|c|c|c|c|c|}
\hline $\begin{array}{l}\text { sno/ } \\
\text { sdRNA }\end{array}$ & Name & Type & Disease/function & Organism & References \\
\hline \multirow{10}{*}{ 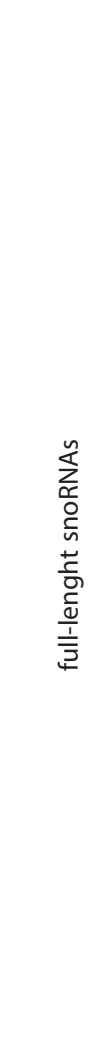 } & $\begin{array}{l}\text { SNORD116 } \\
\text { (HBII-85) }\end{array}$ & $C / D$ & PWS & Clinical specimens & Duker et al., 2010 \\
\hline & $\begin{array}{l}\text { SNORD115 } \\
\text { (HBII - 52) }\end{array}$ & $C / D$ & $\begin{array}{l}\text { PWS/alternative spli- } \\
\text { cing }\end{array}$ & Clinical specimens & $\begin{array}{l}\text { Kishore \& Stamm, } \\
2006\end{array}$ \\
\hline & $\begin{array}{l}\text { SNORD32a (U32a), } \\
\text { SNORD32a (U33), } \\
\text { SNORD34 (U34), SNORD35a } \\
\text { (U35a) }\end{array}$ & $C / D$ & $\begin{array}{l}\text { lipotoxic and oxida- } \\
\text { tive cellular stress } \\
\text { response }\end{array}$ & $\begin{array}{l}\text { Chinese hamster ovary } \\
\text { cells }\end{array}$ & Michel et al., 2011 \\
\hline & SNORD50a (U50) & $C / D$ & $\begin{array}{l}\text { prostate and breast } \\
\text { cancer }\end{array}$ & $\begin{array}{l}\text { Human prostate / breast } \\
\text { cancer cell lines and clini- } \\
\text { cal specimens }\end{array}$ & $\begin{array}{l}\text { Dong et al., 2008; } \\
\text { Dong et al., } 2009\end{array}$ \\
\hline & SNORD42 (U42) & $C / D$ & NSCLC & $\begin{array}{l}\text { Human lung cancer cell } \\
\text { lines and clinical speci- } \\
\text { mens }\end{array}$ & Mei et al., 2012 \\
\hline & SNORD78 (U78) & $C / D$ & NSCLC & Clinical specimens & Zheng et al., 2015 \\
\hline & SNORD113-1 & $C / D$ & $\begin{array}{l}\text { hepatocellular carci- } \\
\text { noma }\end{array}$ & $\begin{array}{l}\text { Human hepatocellular } \\
\text { carcinoma cell lines and } \\
\text { clinical specimens }\end{array}$ & Xu et al., 2014 \\
\hline & SNORD35B (U35B) & $C / D$ & HNSCC & Clinical specimens & Zou et al., 2015 \\
\hline & $\begin{array}{l}\text { SNORD71 } \\
\text { (HBII-239) }\end{array}$ & $C / D$ & $\begin{array}{l}\text { peripheral T-cell lym- } \\
\text { phoma }\end{array}$ & Clinical specimens & Valleron et al., 2012 \\
\hline & h5sn2 & $\mathrm{H} / \mathrm{ACA}$ & brain tumors & Clinical specimens & Chang et al., 2002 \\
\hline \multirow{12}{*}{ 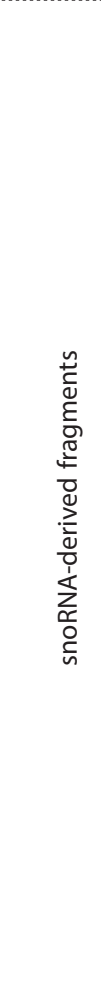 } & $\begin{array}{l}\text { SNORD44, SNORD78, SNORD74, } \\
\text { SNORD81 }\end{array}$ & $C / D$ & prostate cancer & Clinical specimens & $\begin{array}{l}\text { Martens-Uzunova et } \\
\text { al., } 2015\end{array}$ \\
\hline & MBII-52 & $C / D$ & $\begin{array}{l}\text { PWS/alternative } \\
\text { splicing }\end{array}$ & TgPWS mouse model & $\begin{array}{l}\text { Bortolin-Cavaille \& } \\
\text { Cavaille, 2012, Kis- } \\
\text { chore et al., } 2010\end{array}$ \\
\hline & GlsR17, GlsR2 & $C / D$ & miRNA-like functions & Giardia lambia & $\begin{array}{l}\text { Saraiya \& Wang, } \\
2008 \text { Li et al., } 2011\end{array}$ \\
\hline & $\begin{array}{l}\text { SNORD2 (snR39b), } \\
\text { SNORD78 (U78), } \\
\text { SNORD93 (HBIl-336), SNORD100 } \\
\text { (HBII-429),SNORD66 (HBII-142), } \\
\text { SNORD74 (U74), SNORD15a } \\
\text { (U15a) }\end{array}$ & $C / D$ & miRNA-like functions & $\begin{array}{l}\text { HeLa, Jurkat (T cells) and } \\
\text { RPMI8866 (B cell) }\end{array}$ & Brameier et al., 2011 \\
\hline & SNORD3@ (U3) & $C / D$ & miRNA-like functions & HeLa and RPMI8866 & Brameier et al., 2011 \\
\hline & SNORD83a (U83a) & $C / D$ & miRNA-like functions & Jurkat and RPMI8866 & Brameier et al., 2011 \\
\hline & SNORD27 (U27) & $C / D$ & miRNA-like functions & Jurkat & Brameier et al., 2011 \\
\hline & Sno-miRNA-28 & $C / D$ & miRNA-like functions & $\begin{array}{l}\text { Breast cancer cell lines } \\
\text { (MDA-MB-231 MCF10A) }\end{array}$ & Yu et al., 2015 \\
\hline & $\begin{array}{l}\text { SNORA34 (ACA34), } \\
\text { SNORA81 (HBI-61) }\end{array}$ & $\mathrm{H} / \mathrm{ACA}$ & miRNA-like functions & HeLa, Jurkat, RPMI8866 & Brameier et al., 2011 \\
\hline & SNORA36b (ACA36b) & $\mathrm{H} / \mathrm{ACA}$ & miRNA-like functions & HeLa, Jurkat & Brameier et al., 2011 \\
\hline & SCARNA15 (ACA45) & $\mathrm{H} / \mathrm{ACA}$ & miRNA-like functions & HEK293 & Ender et al., 2009 \\
\hline & hsa-miRNA-1291 & $\mathrm{H} / \mathrm{ACA}$ & miRNA-like functions & PANC-1 & Pan et al., 2013 \\
\hline
\end{tabular}


velopment and/or progression of breast cancer (Dong et al., 2009). Interestingly, in breast cancer, homozygosity of the deletion was rare in both, the cases and controls. This difference between prostate cancer and breast cancer could suggest that breast cells are more susceptible to SNORD50a mutation, when comparing to prostate cancer cells.

Head and neck squamous cell carcinoma (HNSCC) is one of the six most common cancers in the world (Ferlay et al. 2008). Recent research aiming at sequencing of a transcriptome of head and neck squamous cell carcinoma tissue revealed 33 significantly deregulated snoRNAs, ranging from about 4-fold to 3-fold for SNORD116-20 and SNORD60, respectively (Zou et al., 2015). Moreover, lower expression of SNORD35B (U35B), a snoRNA downregulated in HNSCC, served as an adverse prognostic factor for patient survival.

\section{SnORNAs IN THE PRADER-WILLI SYNDROME}

The Prader-Willi syndrome (PWS) is a rare genetic disorder manifested by mental retardation, poor muscle tone, incomplete sexual development, cognitive and behavioral disabilities. The major cause of the PWS is the loss of paternal gene expression from a maternally imprinted region 15q11-q13 on chromosome 15. This locus contains numerous copies of snoRNAs and already in the year of 2000 it was reported that three human snoRNAs, expressed in brain tissue, map to the PWS region (de los Santos et al., 2000). Recent discoveries have indeed pointed out that snoRNAs play a significant role in this disease. It has been observed that even a small microdeletion at $15 \mathrm{q} 11.2$ critical region that included the SNORD116 cluster (HBII-85), caused a Prader-Willi syndrome phenotype in an 11-year old patient (Duker et al., 2010). Other studies had shown additional evidence that the same cluster of snoRNAs with unique, yet overlapping microdeletions lead to the loss of a paternal copy of the SNORD116 and PWS phenotype (Sahoo et al., 2008; de Smith et al., 2009).

The genetic loss of SNORD115 (HBII-52) likewise results in the PWS (Kishore \& Stamm, 2006). It appeared that this missing snoRNAs is of special importance in PWS, since it changes the splice site selection. HBII-52 holds a sequence complementary to an alternatively spliced exon $\mathrm{Vb}$ of serotonin receptor 5-HT2CR and therefore regulates the alternative splicing of 5-HT2CR by binding to a silencing element in exon $\mathrm{Vb}$. Lack of HBII-52 leads to defects in pre-mRNA processing and, as a consequence, patients with the Prader-Willi syndrome with loss of paternal HBII-52 gene have different messenger RNA isoforms. As a follow-up of these studies, the same group identified five additional pre-mRNAs (DPM2, TAF1, RALGPS1, PBRM1 and CRHR1) containing alternative exons that are regulated by MBII-52, a mouse homolog of HBII-52 (Kishore et al., 2010). Notably, the analysis of a single member of the MBII-52 cluster had shown that the MBII-52 expressing unit generates shorter RNAs that originate from the full-length MBII-52 snoRNA, through an additional processing steps. These novel RNAs interact with hnRNPs and not with the proteins associated with canonical C/D box snoRNAs. These data indicated that not a traditional C/D box snoRNA MBII-52, but a processed version lacking the snoRNA stem is a predominant MBII-52 RNA missing in PWS. This processed snoRNA is a few nucleotides shorter at the 5' end than the fulllength snoRNA and functions in alternative splice-site selection (Bortolin-Cavaille \& Cavaille, 2012; Kischore et al., 2010).

\section{snoRNAs AS METABOLIC STRESS REGULATORS}

SnoRNAs can be also regulators of metabolic stress response pathways, as observed in Chinese hamster ovary cells (Michel et al., 2011). Four C/D box snoRNAs: SNORD32a (U32a), SNORD32a (U33), SNORD34 (U34) and SNORD35a (U35a) located in the ribosomal protein rpL13a locus, are highly conserved across mammalian species. In addition to their primary role in the ribosomal RNA modification, they also regulate a lipotoxic and oxidative cellular stress responses. Loss of three snoRNAs encoded in the rpL13a locus is sufficient to induce resistance to oxidative and lipotoxic stresses in vitro and prevents the spread of oxidative stress in vivo.

\section{CONCLUSIONS}

Small nucleolar RNAs are a large class of small noncoding RNAs which primarily guide chemical modifications of other RNAs. Rapid development of highthroughput and deep-sequencing technologies has significantly broadened our view of snoRNA characteristics and functionality. However, in higher eukaryotes, many orphan snoRNAs were discovered without known target and function, suggesting that they may play different roles in the cellular life. Moreover, a growing number of evidence clearly shows that many snoRNAs are processed into shorter functional forms, whose generation is still not completely understood. Small nucleolar RNAs may be processed into short miRNA-like RNAs as well as longer sdRNAs. miRNA-like molecules derived from snoRNAs can play a role in regulation of gene expression, whereas many other sdRNAs possess yet undiscovered functions. In the 1990s and at the beginning of the 21 st century many investigations gave numerous information concerning the structure and function of canonical snoRNAs. Recently, many studies revealed new functions of snoRNAs and their fragments. The knowledge in the field of snoRNAs and sdRNAs is still developing and more information is being gained. Thus, in the next years we may discover a great number of novel snoRNAs and sdRNAs functions.

\section{Acknowledgements}

This work was supported by the National Science Centre, Poland [2014/13/D/NZ1/00061 to K.B.-Zे.] and by the Polish Ministry of Science and Higher Education, under the KNOW program.

\section{REFERENCES}

Babiarz JE, Hsu R, Melton C, Thomas M, Ullian EM, Blelloch R (2011) A role for noncanonical microRNAs in the mammalian brain revealed by phenotypic differences in Dgcr8 versus Dicer1 knockouts and small RNA sequencing. RNA 17: 1489-1501. doi 10.1261/ rna. 2442211

Babiarz JE, Ruby JG, Wang Y, Bartel DP, Blelloch R (2008) Mouse ES cells express endogenous shRNAs, siRNAs, and other Microprocessor-independent, Dicer-dependent small RNAs. Genes Dev 22: 2773-2785. doi 10.1101/gad.1705308

Bai B, Yegnasubramanian S, Wheelan SJ, Laiho M (2014) RNA-Seq of the nucleolus reveals abundant SNORD44-derived small RNAs. PLoS One 9: e107519. doi 10.1371/journal.pone.0107519

Belin S, Beghin A, Solano-Gonzalez E, Bezin L, Brunet-Manquat S, Textoris J, Prats AC, Mertani HC, Dumontet C, Diaz JJ (2009) Dysregulation of ribosome biogenesis and translational capacity is 
associated with tumor progression of human breast cancer cells. PLoS One 4: e7147. doi 10.1371/journal.pone.0007147

Bortolin-Cavaille ML, Cavaille J (2012) The SNORD115 (H/MBII-52) and SNORD116 (H/MBII-85) gene clusters at the imprinted Prader-Willi locus generate canonical box C/D snoRNAs. Nucleic Acids Res 40: 6800-6807. doi 10.1093/nar/gks321

Brameier M, Herwig A, Reinhardt R, Walter L, Gruber J (2011) Human box C/D snoRNAs with miRNA like functions: expanding the range of regulatory RNAs. Nucleic Acids Res 39: 675-686. doi $10.1093 /$ nar/gkq776

Burroughs AM, Ando Y, de Hoon MJ, Tomaru Y, Suzuki H, Hayashizaki Y, Daub CO (2011) Deep-sequencing of human Argonauteassociated small RNAs provides insight into miRNA sorting and reveals Argonaute association with RNA fragments of diverse origin. RNA Biol 8: 158-177

Chang LS, Lin SY, Lieu AS, Wu TL (2002) Differential expression of human 5S snoRNA genes. Biochem Biophys Res Commun 299: 196-200

de los Santos T, Schweizer J, Rees CA, Francke U (2000) Small evolutionarily conserved RNA, resembling C/D box small nucleolar RNA, is transcribed from PWCR1, a novel imprinted gene in the Prader-Willi deletion region, which Is highly expressed in brain. $\mathrm{Am}$ J Hum Genet 67: 1067-1082. doi 10.1086/303106

de Smith AJ, Purmann C, Walters RG, Ellis RJ, Holder SE, Van Haelst MM, Brady AF, Fairbrother UL, Dattani M, Keogh JM, Henning E, Yeo GS, O'Rahilly S, Froguel P, Farooqi IS, Blakemore AI (2009) A deletion of the HBII-85 class of small nucleolar RNAs (snoRNAs) is associated with hyperphagia, obesity and hypogonadism. Hum Mol Genet 18: 3257-3265. doi 10.1093/hmg/ddp263

Dong JT (2001) Chromosomal deletions and tumor suppressor genes in prostate cancer. Cancer Metastasis Rev 20: 173-193

Dong XY, Guo P, Boyd J, Sun X, Li Q, Zhou W, Dong JT (2009) Implication of snoRNA U50 in human breast cancer. I Genet Genomics 36: 447-454. doi 10.1016/S1673-8527(08)60134-4

Dong XY, Rodriguez C, Guo P, Sun X, Talbot JT, Zhou W, Petros J, Li Q, Vessella RL, Kibel AS, Stevens VL, Calle EE, Dong JT (2008) SnoRNA U50 is a candidate tumor-suppressor gene at 6q14.3 with a mutation associated with clinically significant prostate cancer. Hum Mol Genet 17: 1031-1042. doi 10.1093/hmg/ddm375

Duker AL, Ballif BC, Bawle EV, Person RE, Mahadevan S, Alliman S, Thompson R, Traylor R, Bejjani BA, Shaffer LG, Rosenfeld JA, Lamb AN, Sahoo T (2010) Paternally inherited microdeletion at $15 \mathrm{q} 11.2$ confirms a significant role for the SNORD116 C/D box snoRNA cluster in Prader-Willi syndrome. Eur J Hum Genet 18: 1196-1201. doi 10.1038/ejhg.2010.102

Ender C, Krek A, Friedlander MR, Beitzinger M, Weinmann L, Chen W, Pfeffer S, Rajewsky N, Meister G (2008) A human snoRNA with microRNA-like functions. Mol Cell 32: 519-528. doi 10.1016/j. molcel.2008.10.017

Falaleeva M, Stamm S (2013) Processing of snoRNAs as a new source of regulatory non-coding RNAs: snoRNA fragments form a new class of functional RNAs. Bioessays 35: 46-54. doi 10.1002/ bies.201200117

Ferlay J, Shin HR, Bray F, Forman D, Mathers C, Parkin DM (2010) Estimates of worldwide burden of cancer in 2008: GLOBOCAN 2008. Int J Cancer 127: 2893-2917. doi 10.1002/ijc.25516

Houseley J, Tollervey D (2008) The nuclear RNA surveillance machinery: the link between ncRNAs and genome structure in budding yeast? Biochim Biophys Acta 1779: 239-246. doi 10.1016/j.bbagrm.2007.12.008

Hutzinger R, Feederle R, Mrazek J, Schiefermeier N, Balwierz PJ, Zavolan M, Polacek N, Delecluse HJ, Huttenhofer A (2009) Expression and processing of a small nucleolar RNA from the EpsteinBarr virus genome. PLoS Pathog 5: e1000547. doi 10.1371/journal. ppat.1000547

Kawaji H, Nakamura M, Takahashi Y, Sandelin A, Katayama S, Fukuda S, Daub CO, Kai C, Kawai J, Yasuda J, Carninci P, Hayashizaki Y (2008) Hidden layers of human small RNAs. BMC Genom 9: 157. doi 10.1186/1471-2164-9-157

Kishore S, Khanna A, Zhang Z, Hui J, Balwierz PJ, Stefan M, Beach C, Nicholls RD, Zavolan M, Stamm S (2010) The snoRNA MBII52 (SNORD 115) is processed into smaller RNAs and regulates alternative splicing. Hum Mol Genet 19: 1153-1164. doi 10.1093/hmg/ ddp 585

Kishore S, Stamm S (2006) The snoRNA HBII-52 regulates alternative splicing of the serotonin receptor 2C. Science 311: 230-232. doi $10.1126 /$ science. 1118265

Li W, Saraiya AAWang CC (2011) Gene regulation in Giardia lambia involves a putative microRNA derived from a small nucleolar RNA. PLoS Negl Trop Dis 5: e1338. doi 10.1371/journal.pntd.0001338

Li Z, Ender C, Meister G, Moore PS, Chang Y, John B (2012) Extensive terminal and asymmetric processing of small RNAs from rRNAs, snoRNAs, snRNAs, and tRNAs. Nucleic Acids Res 40: 67876799. doi 10.1093/nar/gks307

Liao J, Yu L, Mei Y, Guarnera M, Shen J, Li R, Liu Z, Jiang F (2010) Small nucleolar RNA signatures as biomarkers for non-small-cell lung cancer. Mol Cancer 9: 198. doi 10.1186/1476-4598-9-198
Martens-Uzunova ES, Hoogstrate Y, Kalsbeek A, Pigmans B, Vredenbregt-van den Berg M, Dits N, Nielsen SJ, Baker A, Visakorpi $\mathrm{T}$, Bangma C, Jenster G (2015) C/D-box snoRNA-derived RNA production is associated with malignant transformation and metastatic progression in prostate cancer. Oncotarget 6: 17430-17444. doi 10.18632/ oncotarget.4172

Martens-Uzunova ES, Jalava SE, Dits NF, van Leenders GJ, Moller S, Trapman J, Bangma CH, Litman T, Visakorpi T, Jenster G (2012) Diagnostic and prognostic signatures from the small non-coding RNA transcriptome in prostate cancer. Oncogene 31: 978-991. doi 10.1038/onc.2011.304

Mei YP, Liao JP, Shen J, Yu L, Liu BL, Liu L, Li RY, Ji L, Dorsey SG, Jiang ZR, Katz RL, Wang J, YJiang F (2012) Small nucleolar RNA 42 acts as an oncogene in lung tumorigenesis. Oncogene 31: 2794-2804. doi 10.1038/onc.2011.449

Michel CI, Holley CL, Scruggs BS, Sidhu R, Brookheart RT, Listenberger LL, Behlke MA, Ory DS, Schaffer JE (2011) Small nucleolar RNAs U32a, U33, and U35a are critical mediators of metabolic stress. Cell Metab 14: 33-44. doi 10.1016/j.cmet.2011.04.009

Mleczko AM, Celichowski P, Bąkowska-Żywicka K (2014) Ex-translational function of tRNAs and their fragments in cancer. Acta Biochim Pol 61: 211-216.

Pan YZ, Zhou A, Hu Z, Yu AM (2013) Small nucleolar RNA-derived microRNA hsa-miR-1291 modulates cellular drug disposition through direct targeting of ABC transporter ABCC1. Drug Metab Dispos 41: 1744-1751. doi 10.1124/dmd.113.052092

Qu G, Kruszka K, Plewka P, Yang SY, Chiou TJ, Jarmolowski A, Szweykowska-Kulinska Z, Echeverria M, Karlowski WM (2015) Promoter-based identification of novel non-coding RNAs reveals the presence of dicistronic snoRNA-miRNA genes in Arabidopsis thaliana. BMC Genomics 16: 1009. doi 10.1186/s12864-015-2221-x

Sahoo T, del Gaudio D, German JR, Shinawi M, Peters SU, Person RE, Garnica A, Cheung SW, Beaudet AL (2008) Prader-Willi phenotype caused by paternal deficiency for the HBII-85 C/D box small nucleolar RNA cluster. Nat Genet 40: 719-721. doi 10.1038/ ng.158

Saraiya AA, Wang CC (2008) snoRNA, a novel precursor of microRNA in Giardia lamblia. PLoS Pathog 4: e1000224. doi 10.1371/journal.ppat.1000224

Scott MS, Ono M, Yamada K, Endo A, Barton GJ, Lamond AI (2012) Human box C/D snoRNA processing conservation across multiple cell types. Nucleic Acids Res 40: 3676-3688. doi 10.1093/nar/gkr1233

Taft RJ, Glazov EA, Lassmann T, Hayashizaki Y, Carninci P, Mattick JS (2009) Small RNAs derived from snoRNAs. RNA 15: 12331240. doi 10.1261/rna.1528909

Tyczewska A, Bakowska-Żywicka K, Gracz J, Twardowski T (2016) Stress responsive non-protein coding RNAs, Abiotic and biotic stress in plants - recent advances and future perspectives, chapter 7

Valleron W, Laprevotte E, Gautier EF, Quelen C, Demur C, Delabesse E, Agirre X, Prosper F, Kiss T, Brousset P (2012) Specific small nucleolar RNA expression profiles in acute leukemia. Leukemia 26: 2052-2060. doi 10.1038/leu.2012.111

Valleron W, Ysebaert L, Berquet L, Fataccioli V, Quelen C, Martin A, Parrens M, Lamant L, de Leval L, Gisselbrecht C, Gaulard P, Brousset P (2012) Small nucleolar RNA expression profiling identifies potential prognostic markers in peripheral T-cell lymphoma. Blood 120: 3997-4005. doi 10.1182/blood-2012-06-438135

Walkowiak M, Mleczko AM, Bąkowska - Żywicka K (2016) Evaluation of methods for detection of low-abundant snoRNA-derived small RNAs in Saccharomyces cerevisiae. BioTechnologia 97: 19-26. DOI: 10.5114/bta.2016.58540

Xu G, Yang F, Ding CL, Zhao LJ, Ren H, Zhao P, Wang W, Qi ZT (2014) Small nucleolar RNA 113-1 suppresses tumorigenesis in hepatocellular carcinoma. Mol Cancer 13: 216. doi 10.1186/14764598-13-216

Yu F, Bracken CP, Pillman KA, Lawrence DM, Goodall GJ, Callen DF, Neilsen PM (2015) p53 Represses the Oncogenic Sno-MiR-28 Derived from a SnoRNA. PLoS One 10: e0129190. doi 10.1371/ journal.pone. 0129190

Zheng D, Zhang J, Ni J, Luo J, Wang J, Tang L, Zhang L, Wang L, Xu J, Su B, Chen G (2015) Small nucleolar RNA 78 promotes the tumorigenesis in non-small cell lung cancer. J Exp Clin Cancer Res 34: 49. doi 10.1186/s13046-015-0170-

Zou AE, Ku J, Honda TK, Yu V, Kuo SZ, Zheng H, Xuan Y, Saad MA, Hinton A, Brumund KT, Lin JH, Wang-Rodriguez J, Ongkeko WM (2015) Transcriptome sequencing uncovers novel long noncoding and small nucleolar RNAs dysregulated in head and neck squamous cell carcinoma. RNA 21: 1122-1134. doi 10.1261/ rna.049262.114

Zywicki M, Bakowska-Zywicka K, Polacek N (2012) Revealing stable processing products from ribosome-associated small RNAs by deep-sequencing data analysis. Nucleic Acids Res 40: 4013-4024. doi $10.1093 / \mathrm{nar} / \mathrm{gks} 020$ 